\title{
Transmission Line Fault Detection with Mini Weather Station using IoT
}

\author{
Patil Pravin Namdev \\ Department Of Electrical Engineering \\ Kolhapur, India \\ pravinpati19137@gmail.com \\ More Rutuja Goutam \\ Department Of Electrical Engineering \\ Kolhapur, India \\ rutujamore064@gmail.com
}

Department Of Electrical Engineering

Department Of Electrical Engineering

Kolhapur, India
prashant12122gmail.com

Sid Vidya Shankar
Ashokrao Mane Group Of Institutions,
Kolhapur, India
vidyasid1212@gmail.com

Ashokrao Mane Group Of Institutions,
Kolhapur, India
vidyasid1212@gmail.com

\author{
Raut Dhiraj Shantaram \\ Department Of Electrical Engineering \\ Ashokrao Mane Group Of Institutions, Vathar \\ Kolhapur, India \\ dhirajraut2232@gmail.com
}

Prof. Sonali A Palake (Guide)

\author{
Department Of Electrical Engineering
Ashokrao Mane Group Of Institutions, Vathar \\ Kolhapur, India
}

sap@amgoi.edu.in

\begin{abstract}
The fault occurred in transmission line is very much dangerous for the locality. In locality the fault occurrence is more as compared to outer transmission line. In our prototype we design a model which is to be detect the fault in transmission line by comparing the voltage signal between the transmission line and a reference value, the reference value is predetermined and if the transmission line voltage is more than or less than reference value then fault is to be shown in display. The information regarding fault occurrence in particular phase is send to web page via IOT device which is NODE MCU(Esp8266) and also shown in display. The Voltage sensor is used to sense the voltage and send output to microcontroller IC. Here microcontroller IC ATMEGA 328P is used in this IC programming is done which compare the voltage signal and send output to IOT module and display. Similarly, climate is the condition of the environment, to the extent that it is hot or chilly, wet or dry, quiet or stormy, clear or overcast. Checking the climate conditions physically is troublesome. Here on this paper the weather station is based totally on IoT (internet of things). Such a framework contains sensor like DHT11 that detects temperature and humidity. The sensor is associated with an e-bulletin board and ESP8266 board that is a low fee Wi-Fi module. By keeping the embedded devices in the environment for tracking enables us to know the college campus weather. The execution of the climate observing framework needs to convey the sensor gadgets in the surrounding for gathering the information and analysis
\end{abstract}

Keywords - Internet of things, Microcontroller IC ATMEGA $328 P$, Arduino software Internet of things, temperature and humidity sensor.

\section{INTRODUCTION}

Internet of Things (IoT)- IoT is the future innovation of associating the whole world at one place. Every one of the articles, things and sensors can be associated with sharing the information acquired in different areas and process/investigations that information for planning the applications like activity flagging, versatile wellbeing checking in therapeutic applications and mechanical security guaranteeing strategies, and so on. According to the estimation of innovative specialists, 50 billion articles will be associated in IoT by 2020 . IoT offers an extensive variety of network of gadgets with different conventions and different properties of utilizations for getting the total machine to machine cooperation.
Transmission line fault detection- It is known that when a fault occurs in overhead transmission line system then instantaneous changes in voltage and current at the point of fault generate high frequency. Electromagnetic impulses called travelling wave which propagate along the transmission line in both directions away from the fault point. The electric power infrastructure is highly end angered against many form of natural and spiffy physical events. Which can skeptical affect the overall performance and stability of the grid. The fault impedance being low. The fault current is relatively high, during the fault. The power flow is diverted towards the fault and supply to the neighbouring zone is affected Voltage become unbalanced. It is important to detect the fault as early as possible that is why a kit is being made using microcontroller to make its process faster. The transmission line conductor resistance and inductance distributed uniformly along the length of the line. Travelling wave fault location methods are usually more suitable for application long lines. Power transmission lines employ at 50- HZ are more than $80-\mathrm{km}$ long are considered to have the properties of voltage and current wave that travel on the line have the properties of voltage and current wave that travel on the line with finite speed of propagation. Traveling wave methods for transmission line fault location have been reported since a long time. Following developments employ high speed digital recording technology by using the traveling wave transients created by the fault. Currently, the electric power infrastructure is more vulnerable against many forms of natural and malicious physical events [1], which is directly affect the stability of grid. There will be some parameter which is affected. With this, there is an approaching need to equip the age old transmission line infrastructure with a high performance data communication network, that supports future operational requirements like real in the time record and control necessary for smart grid integration [2], [3]. Due to this technique the real time monitoring is necessary. Many electric power transmission companies have primarily depended on circuit indicators to detect the faulty sections of their transmission lines. However, there are still challenges in identifying the exact location of these faults. Although fault indicator technology has provided a flexible means to locate permanent faults, the technical crew and patrol teams still has to physically patrol and inspect the devices for large duration to detect faulty sections of their transmission lines. Wireless sensor based monitoring of transmission lines 
provides a solution for several of these disquiet like real time structural awareness, faster fault localization, accurate fault diagnosis by identification and difference of electrical faults from the mechanical faults, cost reduction due to condition based maintenance rather than periodic maintenance, etc. These implementations identify stringent requirements such as fast delivery of enormous amount of highly reliable data. The success of these appeal depends on the design of cost effective and reliable network architecture with a fast response time. The network must be able to transport confidential information such as current state of the transmission line and control information to and from the transmission grid. This research provides an economical substructure to design a real time data transmission network. To observe the status of the power system in real time, sensors are put in various components in the power network..

Weather monitoring- Climate is driven via pneumatic force (temperature and humidity) contrasts between one place and another. These weight and temperature contrasts can happen because of the sun edge at a specific spot, which fluctuates by scope from the tropics. The climate is a confused framework, so little changes to one a player in the framework can develop to effectively affect the framework all in all. This makes it hard to precisely foresee climate in excess of a couple of days ahead of time, however climate forecasters are ceaselessly attempting to expand this point of confinement through the logical investigation of climate, meteorology. It is hypothetically difficult to make helpful day-today forecasts more than around two weeks ahead, forcing a maximum point of confinement to potential for enhanced expectation aptitude. The framework is furnished with all sensor gadgets should goes about as customer to send the information to the web server. For setting up an association between the sensor system and web, we utilized a $\mathrm{Wi}-\mathrm{Fi}$ module as an extra correspondence interface controlled by the microcontroller. A Wi-Fi module requires a wellspring of remote web association. Once designing the Wi-Fi module with a web source, it goes about as customer and sends the sensor information recovered by the microcontroller. The criteria of associating every one of the sensors to the web are Web of Things (IoT). The idea of associating the electronic gadgets, sensors. - Store and retrieve local weather.

\section{BLOCK DIAGRAM}

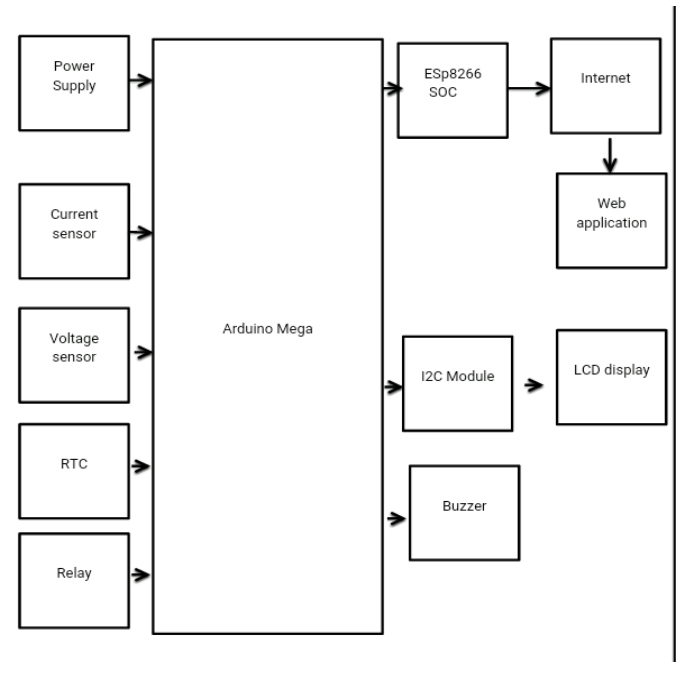

Fig. 1. Block Diagram

\section{Circuit Diagram-}
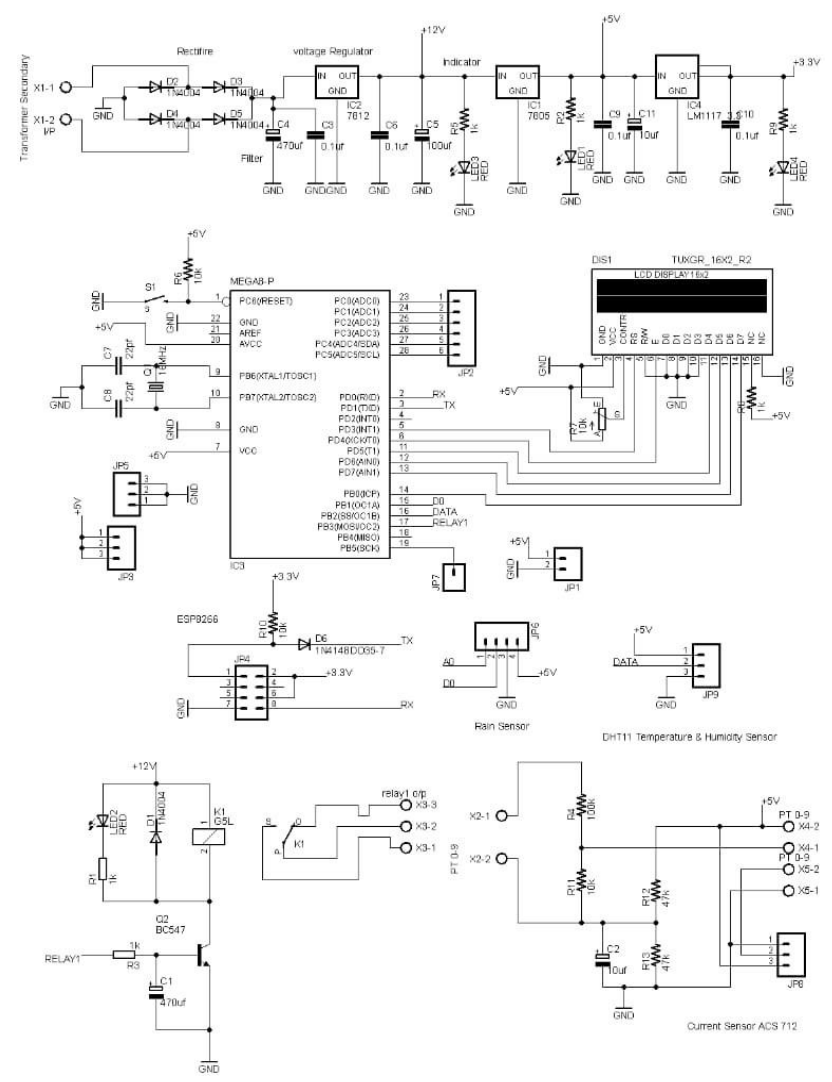

Fig. 2. Circuit Diagram

\section{COMPONENT LIST}

- Switches

- Microcontroller ATMEGA328P

- $\quad$ LCD Display $(16 * 2)$

- $\quad$ Wi -Fi Module Node MCU

- Voltage and Current Sensors

- Resistors

- Relays

- buzzer

- rain sensor

- DHT11 Temperature and Humidity sensor

\section{WORKING AND OPERATIONS}

- Our prototype is used to detect the fault, which has occurred in transmission line.

- By using ATMEGA328P microcontroller, optocoupler, LCD. A prototype is assemble with a set of resistor, cable length in $\mathrm{km}$, by using set of switches made to creation of fault in prototype.

- A $230 \mathrm{v}$ ac supply is fed to the terminal, let us consider the terminals (R,Y,B)we took supply and fed to the terminal there one resistor connected with diode, resistor rating is $470 \mathrm{k}$ ohm and diode which rectify the voltage signal and gives variable DC as a output. 
- A capacitor which is connected in parallel which is used to keep out all unwanted signal as well as gives constant DC supply.

- The DC supply is then gives to optocoupler and input Side of optocoupler the DC supply is present that glows the LCD.

- Inside the optocoupler one LED and transistor are present. The transistor is NPN transistor, the base terminal is sense the radiation of LED and the current flow inside the transistor from collector to emitter.

- The emitter terminal is connected to ground and the collector terminal is connected to IC ATMEGA328P.

- $\quad$ The program is done in IC ATMEGA328P which compare the voltage level and gives the output on LCD and Wi-Fi module result shown on PC and screen. 6. Internet of things (IOT) The internet of things or IOT, is a system which is connected between the devices, analog, mechanical and digital machines, objects, animals or people that are provided with unique identifiers (UIDs) and the ability to sending data over a network without requiring human-to-human or human-to-computer interaction.

- Humidity and Temperature Sensor (DHT11)DHT11 (Fig 3) interfaces with ESP8266 board for dampness (in \%) and temperature (in degree Celcius) estimation utilizing single wire serial interface (SPI). For dampness estimation resistive compose segment and for temperature estimation negative temperature coefficient (NTC) segment is utilized by this sensor

- Software Methodology: The whole programming piece of the framework should be possible in C dialect. Right off the bat, we need to introduce the ESP8266 by sending a couple AT orders. Introduction process incorporates, checking the correspondence with ESP8266 to microcontroller, looking for a $\mathrm{Wi}-\mathrm{Fi}$ organize inside its range and interfacing the Wi-Fi module to that system by getting validated with required accreditations. After the instatement procedure, we need to program for arranging the Wi-Fi module as a TCP/IP customer. While designing the ESP8266, checking the affirmation is critical to guarantee that the module is arranged effectively.

\section{- Result}

The three terminal is connected to the switch when one switch is one and remaining two switches are closed then the output shown is display is terminal $\mathrm{Y}$ and $\mathrm{B}$ has been faulted (Supposed terminal is R,Y,B and terminal $\mathrm{R}$ is connected to supply i.e. switch is $\mathrm{ON}$ and other switch which is connected between terminal Y and B is OFF hence its shows the fault.) your paper; use the scroll down window on the left of the MS Word Formatting toolbar.

Every one of the modules was planned and every one of the segments was gathered. The testing of every module was completed effectively. The sensor readings were successfully recovered in a steady situation and put away in documents. The records were then foreign to exceed expectations naturally utilizing macros and the information was purged and arranged for a neater portrayal. Therefore the testing stage was finished.This examination was performed in a controlled way. Hence, there is a need to direct further tests in situations more like genuine climate conditions.

A. Applications

- Used in transmission line

- Used in distribution line

- Used in villages

B. Future scope

- Underground Line fault Detection

- Data Logging

- This model can be additionally extended to screen the creating urban communities and modern zones for contamination observing.

C. Advantages

- Work in real time response inter

- Coverage area in large compared to existing system

- cost efficient

- Devices enable by wireless communication

- Number of components are used

- Economically reliable and low cost

- It will give a skillful technique to recording ongoing climate readings and help agriculturists whose business relies upon the climate in a nation like India to create better quality products.

\section{CONCLUSION}

The model design in such a way to solve the problems faced by consumer. By using such method, we can easily detect the fault and resolve it. It is highly reliable and locate the fault in three phase transmission line and also supposed to data storage. It works on real time so we maintain all data sheet and avoid the future problem in transmission line.

This model gives a proficient and minimal effort answer for persistent checking of condition.

\section{ACKNOWLEDGMENT}

I am glad to display this paper on "Transmission Line Fault Detection with Mini Weather Station using IoT" in the wake of finishing it effectively. I offer my true thanks to our Principal Prof. P.B. Ghewari, for giving the help. I healthily thank our Head of Department, Prof. A.A. Malgave, Dept. of Electrical Engineering, AMGOI and Our project guide Prof. S.A. Palake for consistent support and motivation in taking up this smaller than normal undertaking.

\section{REFERENCES}

[1] H. Li, G. W. Rosenwald, J. Jung, and C. Liu, "Strategic power infrastructure defense," Proc. IEEE, vol. 93, no. 5, pp. 918-933, May 2005. 
[2] G. Vidhya Krishnan, R.Nagarajan, T. Durka,M.Kalaiselvi, M.Pushpa and S. Shanmuga priya, "Vehicle Communication System Using LiFi Technology," International Journal of Engineering and Computer Science (IJECS), Volume 6, Issue 3, pp. 20651-20657, March 2017.

[3] J. Chandramohan, R. Nagarajan, K. Satheeshkumar, N. Ajith kumar, P. A. Gopinath and S.Ranjith kumar,"Intelligent Smart Home Automation and Security System Using Arduino and Wi-Fi," International Journal of Engineering And Computer Science (IJECS), Volume 6, Issue 3, pp. 20694-20698, March 2017.

[4] Arshdeep Bahga, Vijay Madisetti, 'Internet of Things: A Hands on Approach" Universities Press"., 2015

[5] Karthik Krishnamurthi, Suraj Thapa, Lokesh Kothari, Arun Prakash "Arduino Based Weather Monitoring System" International Journal of Engineering Research and General Science Volume 3, Issue 2, March- April, 2015.

[6] Bulipe Srinivas Rao, Prof. Dr. K. Srinivasa Rao, Mr. N. Ome. "Internet of Things (IOT) Based Weather Monitoring system". International Journal of Advanced Research in Computer and
Communication Engineering ISO 3297:2007 Certified Vol. 5, Issue 9, September 2016.

[7] Kondamudi Siva Sai Ram, A.N.P.S.Gupta. "IoT based Data Logger System for weather monitoring using Wireless sensor networks", (IJETT) - Volume 32 Number 2- February 2016

[8] V. C. Gungor and F. C. Lambert, "A survey on communication networks for electric system automation," Comput. Netw. vol. 50, no.7, pp.877-897, May 2006.[4]

[9] P. Ramachandran, V. Vittal, and G. T. Heydt, "Mechanical state estimation for overhead transmission lines with level spans," IEEE Trans. Power Syst., vol. 23, no. 3, pp. 908-915, Aug. 2008.

[10] R. Nagarajan and S. Sathishkumar, K. Balasubramani, C. Boobalan, S. Naveen and N. Sridhar, "Chopper Fed Speed Control of DC Motor Using PI Controller," 7. IOSR-Journal of Electrical and Electronics Engineering (IOSR-JEEE), Volume 11, Issue 3, Ver.I, pp. 65-69, May- Jun. 2016.

[11] P. Zhang, F. Li, and N. Bhatt, "Next generation monitoring, analysis, and control for the future smart control center," IEEE Trans. Smart Grid, vol. 1, no.2, pp. 186-192, Sep. 2010 